\title{
Effects of the addition of low-dose ketamine to propofol anesthesia in the dental procedure for intellectually disabled patients
}

\author{
Akira Hirayama', Ken-ichi Fukuda², Yoshihiko Koukita ${ }^{3}$, Tatsuya Ichinohe ${ }^{3}$ \\ 'Hirayama Dental Clinic, Chiba, Japan \\ ${ }^{2}$ Division of Special Needs Dentistry and Orofacial Pain, Department of Oral Health and Clinical Science, Tokyo Dental College, Tokyo, \\ Japan \\ ${ }^{3}$ Department of Dental Anesthesiology, Tokyo Dental College, Tokyo, Japan
}

\begin{abstract}
Background: This study aimed to examine whether the combination of low-dose ketamine and propofol in deep sedation is clinically useful in controlling the behavior in intellectually disabled patients who are typically extremely noncooperative during dental procedures.

Methods: A total of 107 extremely noncooperative intellectually disabled adult patients were analyzed. In all patients, deep sedation was performed using either propofol alone (group P) or using a combination of propofol and $0.2 \mathrm{mg} / \mathrm{kg}$ or $0.4 \mathrm{mg} / \mathrm{kg}$ ketamine (groups PK0.2 and PK0.4, respectively). The procedures were performed in the order of insertion of nasal cannula into the nostril, attachment of mouth gag, and mouth cleaning and scaling. The frequency of patient movement during the procedures, mean arterial pressure, heart rate, peripheral oxygen saturation, recovery time, discharge time, and postoperative nausea and vomiting were examined. Results: The three groups were significantly different only in the frequency of patient movement upon stimulation during single intravenous injection of propofol and scaling.

Conclusion: For propofol deep sedation, in contrast to intravenous injection of propofol alone, prior intravenous injection of low-dose ketamine $(0.4 \mathrm{mg} / \mathrm{kg})$ is clinically useful because it neither affects recovery, nor causes side effects and can suppress patient movement and vascular pain during procedures.
\end{abstract}

Keywords: Dental Procedure; Intellectually Disabled Patients; Ketamine; Propofol; Vascular Pain.

This is an Open Access article distributed under the terms of the Creative Commons Attribution Non-Commercial License (http://creativecommons.org/licenses/by-nc/4.0/) which permits unrestricted non-commercial use, distribution, and reproduction in any medium, provided the original work is properly cited.

\section{INTRODUCTION}

Due to the challenge in gaining the cooperation of intellectually disabled patients when performing dental procedures, behavior control using drugs, such as intravenous moderate sedation, deep sedation, and intubated general anesthesia, is often required [1,2]. Among these, in cases in which behavior control poses a significant challenge, unconscious sedation, namely, deep sedation or intubated general anesthesia, becomes necessary. For follow-ups and mouth cleaning of extremely noncooperative intellectually disabled patients who have undergone multiple teeth intensive treatment under intubated general anesthesia, unconscious sedation is necessary, even in short procedures; in this case, deep sedation is often performed.

Drugs used for deep sedation in outpatients undergoing

Received: December 3, 2019 • Revised: May 3, 2019 • Accepted: June 17, 2019

Corresponding Author: Ken-ichi Fukuda, Division of Special Needs Dentistry and Orofacial Pain, Department of Oral Health and Clinical Science, Tokyo Dental College, 9-18, Misaki-cho, Chiyoda-ku, Tokyo 101-0061, Japan

Tel: +81-3-6380-9243 Fax: +81-3-5275-1959 E-mail: kfukuda@tdc.ac.jp

Copyright(c) 2019 Journal of Dental Anesthesia and Pain Medicine 
day surgery must have certain properties, including rapid onset of action and ability to provide adequate patient movement suppression during procedures. Moreover, good recovery must be ensured, including minimal respiratory and circulatory depression, short time to awakening, and absence of postoperative discomfort.

Propofol, which activates inhibitory GABA receptors, allows rapid recovery and is considered suitable for deep sedation in outpatients undergoing day surgery $[3,4]$. However, this drug has a few drawbacks including the possibility of patient movement in the middle of a procedure and vascular pain at the time of administration because it has no analgesic effect. Furthermore, it may cause respiratory or circulatory depression due to sympathoinhibition [5]. In contrast to propofol, ketamine, which competes with excitatory NMDA receptors, possesses the property of maintaining an analgesic and sympathomimetic effect and airway reflex [6]. Additionally, prior administration of ketamine is reported to relieve vascular pain that occurs during propofol administration $[7,8]$. Nevertheless, ketamine also has drawbacks, including the possibility of postoperative hallucination and vomiting [9]. In contrast, propofol acts to suppress postoperative vomiting and prevent nightmares caused by ketamine $[3,4]$. Therefore, to compensate for the shortcomings of these two drugs, deep sedation using a combination of propofol and ketamine has been adopted in examinations, emergency medical care, and minor surgeries in outpatients. However, in most cases, midazolam and fentanyl are used simultaneously [10-12]. There are few reports addressing the use of deep sedation via intravenous anesthesia, using only propofol and ketamine in dental treatments. For extremely noncooperative intellectually disabled patients who have undergone multiple teeth intensive treatment under intubated general anesthesia, deep sedation using a combination of propofol and low-dose ketamine has been adopted at the Chiba City Health and Medical Center (Chiba, Japan) during mouth cleaning and scaling in regular follow-ups, a few months after the intensive treatment.

We conducted a retrospective study to examine whether prior injection of low-dose ketamine during propofol deep sedation, compared with injection of propofol alone, was able to suppress patient movement during treatments and mitigate vascular pain. Moreover, we also assessed whether it is able to prevent respiratory and circulatory depression caused by propofol, exerts effects on patient recovery, or causes side effects such as postoperative vomiting. In other words, we examined whether the combination of low-dose ketamine and propofol in deep sedation is clinically useful in controlling behavior in intellectually disabled patients who are typically extremely noncooperative during dental procedures.

\section{MATERIALS AND METHODS}

This study was conducted after obtaining approval from the Ethics Committee of Tokyo Dental College (Tokyo, Japan; approval number 778) and written approval from the Facility Director of Chiba City Health and Medical Center.

A total of 126 patients underwent regular follow-ups and mouth cleaning and scaling under deep sedation 3-6 months after undergoing intensive treatment for multiple teeth under intubated general anesthesia at Chiba City Health and Medical Center within the 11-year period from April 2004 to March 2015. Among these patients, 107 extremely noncooperative intellectually disabled adult patients, with American Society for Anesthesiologists Class 1 and complete records, were included in the analysis. In all patients, deep sedation was performed by dental anesthesiologists using either propofol alone (group P) or using a combination of propofol and 0.2 $\mathrm{mg} / \mathrm{kg}$ or $0.4 \mathrm{mg} / \mathrm{kg}$ ketamine (groups PK0.2 and PK0.4, respectively).

The patients discontinued drinking and fasted from midnight before the day of surgery and visited the hospital accompanied by their guardian without any premedication. After entering the procedure room, an automatic sphygmomanometer, electrocardiogram, and 


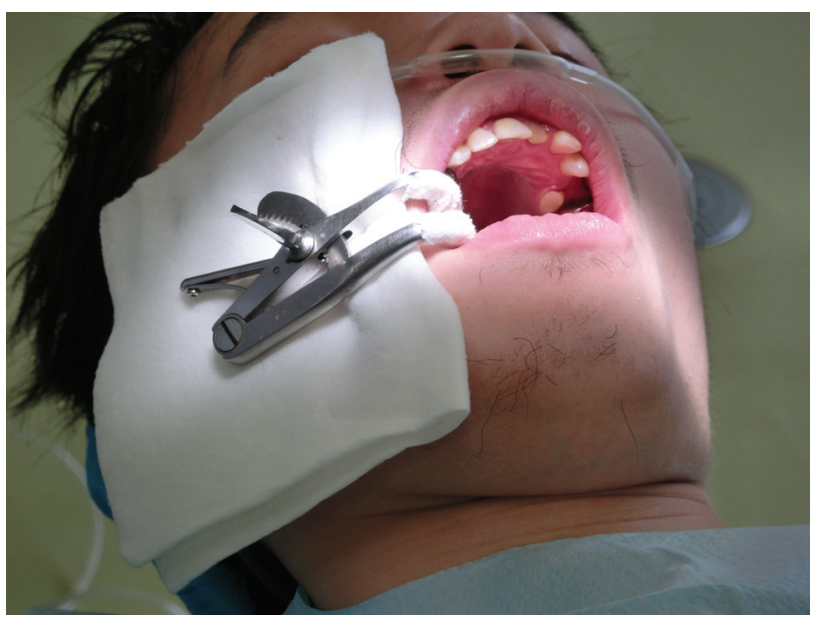

Fig. 1. Nasal cannula and mouth gag: patient movement was observed when the nasal cannula and mouth gag were inserted in the dental procedure.

percutaneous oxygen saturation $\left(\mathrm{SpO}_{2}\right)$ meter were attached to the patients while in supine position. Next, a 24-G intravenous indwelling needle was inserted into the superficial forearm vein, and intravenous drip infusion of acetated Ringer's solution was started at a rate of 100 $\mathrm{mL} / \mathrm{h}$. Patients in group $\mathrm{P}$ underwent deep sedation maintained with continuous injection at $5-8 \mathrm{mg} / \mathrm{kg} / \mathrm{h}$ after induction with a single intravenous injection of propofol $1.2 \mathrm{mg} / \mathrm{kg}$. For patients in groups PK0.2 and PK0.4, propofol was used for induction and maintenance, similar to that in group P, 1 min after single intravenous injection of ketamine $0.2 \mathrm{mg} / \mathrm{kg}$ or $0.4 \mathrm{mg} / \mathrm{kg}$. Procedures were started after the patients closed their eyes and lost responsiveness to calls of their name. The procedures were performed in the order of insertion of nasal cannula into the nostril (Fig. 1), attachment of mouth gag (Fig. 1), and mouth cleaning and scaling. After insertion of the nasal cannula, the patients were allowed to receive oxygen at a rate of $2 \mathrm{~L} / \mathrm{min}$. An additional injection of propofol $(10 \mathrm{mg})$ was administered each time patient movement was observed during the procedures. Intraoperative monitoring was performed through noninvasive arterial blood pressure (systolic pressure, diastolic pressure, and mean blood pressure [MBP]), heart rate (HR), and $\mathrm{SpO}_{2}$. Blood pressure and $\mathrm{HR}$ were measured and recorded every 5 min until completion of
Table 1. Pattern of response to IV administration of propofol as a bolus

1. No response

2. Movement at the wrist only

3. Movement/withdrawal involving arm only (elbow/shoulder)

4. Generalized response - withdrawal or movement in more than one extremity, cough, or breath-holding

the procedures. $\mathrm{SpO}_{2}$ was continuously measured using a pulse oximeter (Pulsox, Konica Co., Ltd., Tokyo, Japan), and all data were recorded. All measured values were then converted into histograms and recorded. On completion of procedures, continuous propofol injection was discontinued, and oxygen inhalation through the nasal cannula was continued until the patients were confirmed to have fully awakened. In terms of homereadiness assessment, patients were allowed to return to their facilities accompanied by their guardian after reaching an Aldrete score $>10$ points [13] and modified postanesthesia discharge scoring system (MPADSS) score $>9$ points [14].

Survey items in the present study included the patient background; duration of procedure; time to eye opening; total propofol dose; number of patients with additional propofol injection; number of times additional propofol injection was required; time to discharge and frequency of patient movement (during initial propofol injection and at each time point of nasal cannula insertion, mouth opening by gag, and scaling); time-dependent changes in MBP and HR during procedures and their respective coefficients of variation; $\mathrm{SpO}_{2}$ histograms; and occurrence of postoperative vomiting and abnormal behaviors, such as violent behaviors and making peculiar sounds, after anesthesia. Time to eye opening was defined as the duration from the discontinuation of continuous propofol injection until eye opening upon name call. Patient movement during initial propofol injection was evaluated based on the 4-point scale described by Shevchenko et al. [15] (Table 1), which indicates the magnitude of escape behaviors.

\section{Statistical analysis}

Statistical analysis was performed using nonrepeated measures ANOVA for intergroup comparisons of sex, 
Table 2. Demographic data and clinical characteristics in the three groups

\begin{tabular}{|c|c|c|c|c|c|}
\hline & & Group P & Group PK0.2 & Group PK0.4 & P-value \\
\hline $\mathrm{N}$ & & 35 & 34 & 38 & \\
\hline $\operatorname{Sex}(M / F)$ & & $29 / 6$ & $29 / 5$ & $34 / 4$ & NS \\
\hline Age (years) & & $29.5(8.6)$ & $25.8(7.6)$ & 27.7 (8.3) & NS \\
\hline Weight $(\mathrm{kg})$ & & $59.3(16.7)$ & $61.0(17.6)$ & $63.6(16.1)$ & NS \\
\hline Total propofol dose (mg) & & $363.7(112.4)$ & $350.3(108.9)$ & $368.7(95.4)$ & NS \\
\hline $\begin{array}{l}\text { Additional propofol injection } \\
\text { Case }(\mathrm{n})-\text { [times] }\end{array}$ & & $5-[8]$ & $1-[1]$ & $2-[2]$ & NS \\
\hline Duration of procedure (min) & & $31.6(7.1)$ & $28.5(4.0)$ & $31.3(9.4)$ & NS \\
\hline Time to eye opening (min) & & $16.1(3.9)$ & $15.4(3.7)$ & $16.8(3.3)$ & NS \\
\hline Time to discharge (min) & & $37.6(13.1)$ & $35.4(9.8)$ & $34.7(9.1)$ & NS \\
\hline \multirow{2}{*}{$\begin{array}{l}\text { Coefficient of } \\
\text { variation }(\%)\end{array}$} & MABP & 8.8 (3.3) & $7.7(1.9)$ & $9.7(3.7)$ & NS \\
\hline & $H R$ & $9.0(3.5)$ & $7.6(3.1)$ & $8.4(3.8)$ & NS \\
\hline Vomiting (\%) & & 0 & 0 & 2.6 & NS \\
\hline $\begin{array}{l}\text { Abnormal behavior } \\
\text { after anesthesia (\%) }\end{array}$ & & 0 & 0 & 0 & NS \\
\hline \multirow[t]{2}{*}{$\mathrm{SpO}_{2}$ histogram (\%) } & $<95 \%$ & $27.0(28.6)$ & $16.0(19.0)$ & $16.2(17.2)$ & NS \\
\hline & $<90 \%$ & $8.1(14.3)$ & $4.1(9.8)$ & $7.3(14.7)$ & NS \\
\hline
\end{tabular}

Table 3. Incidence of patient movement during procedures

\begin{tabular}{lcccc}
\hline & Group P & Group PK0.2 & Group PK0.4 & P-value \\
\hline Propofol injection (\%) & 25.7 & 5.8 & 0 & $<0.01$ \\
Insertion of nasal cannula (\%) & 17.1 & 5.8 & 0 & NS \\
Mouth opening by gag (\%) & 25.7 & 14.7 & 5.2 & NS \\
Scaling (\%) & 45.7 & 35.2 & 10.5 & $<0.01$ \\
\hline
\end{tabular}

age, weight, total propofol dose, duration of procedure, time to eye opening, time to discharge, coefficients of variation of MBP and $\mathrm{HR}$, and MBP and $\mathrm{HR}$ at each time point and repeated measures ANOVA for timedependent intergroup comparison of MBP and HR. Additionally, the intergroup comparisons of the frequency of number of cases with additional propofol injection and the frequency of patient movement during procedures were performed using the $\mathrm{m} \times \mathrm{n}$ chi-squared test. Differences with a P-value $<0.05$ were considered statistically significant.

\section{RESULTS}

There was no significant difference in age, weight, sex ratio, duration of procedure, time to eye opening, total propofol dose, frequency of number of cases with additional propofol injection, and time to discharge in the 3 groups (Table 2).
There was a significant difference only in frequency of patient movement upon stimulation during single intravenous injection of propofol and scaling in the 3 groups (Table 3). The magnitude of patient movement during initial propofol injection was grade 3 in 4 patients, grade 2 in 5, and grade 1 in 26 in group P; grade 2 in 2 patients and grade 1 in 32 in group PK0.2; and grade 1 in all patients in group PK0.4. There was a significant difference in the 3 groups when a grade $>2$ was considered as patient movement.

In all 3 groups, time-dependent changes in MBP and $\mathrm{HR}$ during the procedures were not significant when compared with time-dependent changes in MBP and HR immediately before anesthetic administration. Additionally, there was no significant difference in the 3 groups at all time points.

Furthermore, there was no significant difference in the 3 groups with regard to MBP, HR, and their respective coefficients of variation (Figs. 2 and 3) or in $\mathrm{SPO}_{2}$ profiles during the procedures (Table 2). There was no 


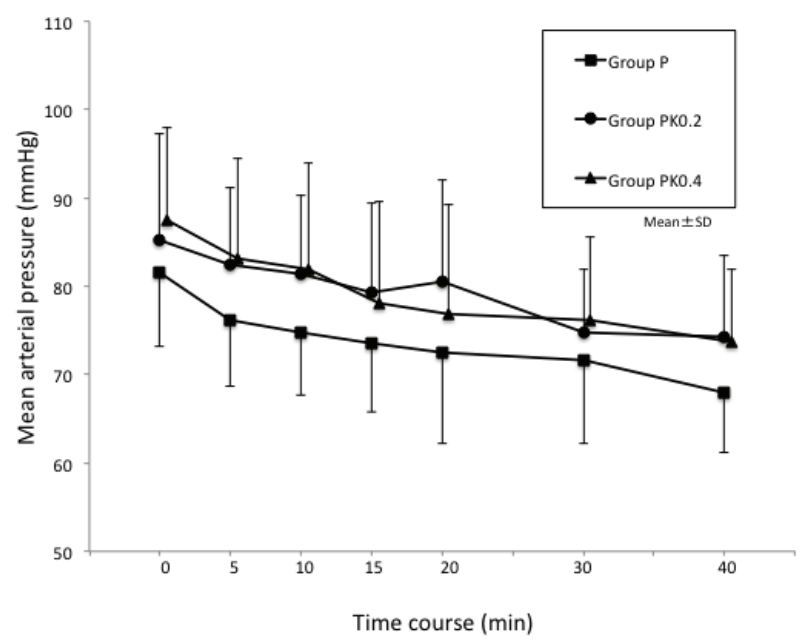

Fig. 2. Changes in mean arterial blood pressure (MABP) during procedures: in all 3 groups, time-dependent changes in MABP during the procedures were not significant, and there was no significant difference in the 3 groups at all time points.

significant difference in the frequency of postoperative vomiting in the 3 groups (Table 2), and no abnormal behaviors after anesthesia were observed (Table 2).

\section{DISCUSSION}

At the Chiba City Health and Medical Center, deep sedation with either propofol alone or a combination of propofol and ketamine $0.2 \mathrm{mg} / \mathrm{kg}$ or $0.4 \mathrm{mg} / \mathrm{kg}$ is performed in extremely noncooperative intellectually disabled patients who have undergone intensive treatment on multiple teeth under intubated general anesthesia during follow-up(s), mouth cleaning, and scaling a few months after the intensive treatment. In this study, we retrospectively compared patient background, frequency of patient movement under deep sedation, changes in circulatory and respiratory system parameters, and occurrence of postoperative vomiting and abnormal behaviors under 3 types of deep sedation through biomonitoring records and anesthesia charts. We successfully confirmed significant differences in the frequency of patient movement during initial propofol injection and scaling.

Deep sedation with propofol, in place of traditionally

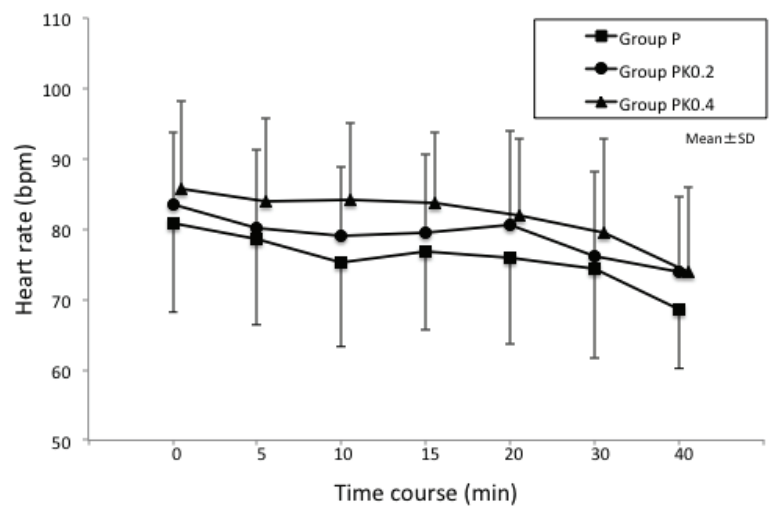

Fig. 3. Changes in heart rate (HR) during procedures: in all 3 groups, time-dependent changes in HR during the procedures were not significant, and there was no significant difference in the 3 groups at all time points.

used barbiturate(s), has become the preferred anesthetic method for dentoalveolar surgery and office oral and maxillofacial anesthesia [16]. The recommended administration method begins with induction through a bolus injection of $1 \mathrm{mg} / \mathrm{kg}$, followed by maintenance through continuous injection at a rate of $4-6 \mathrm{mg} / \mathrm{kg} / \mathrm{h}$ [17]. Because the subjects in this study were intellectually disabled and extremely noncooperative, and reliable patient-movement control was necessary, anesthesia was performed through induction using a bolus injection of $1.2 \mathrm{mg} / \mathrm{kg}$, followed by maintenance with continuous injection at a rate of $5-8 \mathrm{mg} / \mathrm{kg} / \mathrm{h}$. This rate of administration resulted in patient movement under deep sedation with propofol alone at $17.1 \%$ during insertion of nasal cannula; $25.7 \%$ during mouth opening by gag, and $45.7 \%$ during scaling. In contrast, in the case of deep sedation with combined propofol-ketamine $0.2 \mathrm{mg} / \mathrm{kg}$, patient movement was $5.8 \%$ during insertion of nasal cannula, $14.7 \%$ during mouth opening by gag, and $35.2 \%$ during scaling. Furthermore, in the case of deep sedation with combined propofol-ketamine $0.4 \mathrm{mg} / \mathrm{kg}$, patient movement was suppressed to nil during insertion of nasal cannula, 5.2\% during mouth opening by gag, and $10.5 \%$ during scaling. Akin et al. [18] compared a propofol-alone group, which received induction through bolus injection of propofol $1.2 \mathrm{mg} / \mathrm{kg}$, followed by management through additional half-dose propofol injection in combination with hypnagogic state, and a group in which ketamine 
$0.5 \mathrm{mg} / \mathrm{kg}$ was used in combination with propofol during initial bolus injection for anesthesia in auditory brainstem response testing in 60 children. The authors reported that the combination with ketamine was clinically useful in sparing the amount of propofol used and preventing hypoxia because supplemental propofol injection was reduced by the addition of ketamine [18]. Moreover, Cillo [19] confirmed the effectiveness of continuous intravenous propofol injection $5.5 \mathrm{mg} / \mathrm{kg} / \mathrm{h}$ and ketamine 0.55 $\mathrm{mg} / \mathrm{kg} / \mathrm{h}$, compared with continuous intravenous injection at a rate of $6 \mathrm{mg} / \mathrm{kg} / \mathrm{h}$ of propofol alone, in anesthesia in wisdom tooth extraction. The authors reported the clinical usefulness of the combination of ketamine and propofol in sparing the amount of propofol used and ensuring rapid recovery. Furthermore, Canpolat et al. [20] reported a higher satisfaction level of surgeons with tooth extraction in noncooperative pediatric patients using bolus injection of a combination of propofol $0.5 \mathrm{mg} / \mathrm{kg}$ and ketamine $0.5 \mathrm{mg} / \mathrm{kg}$ compared with that using bolus injection of propofol $1 \mathrm{mg} / \mathrm{kg}$ alone. From these reports, it can be inferred that the addition of a small amount of ketamine to propofol anesthesia contributes to appropriate sedative effects while sparing the amount of propofol used. Hypnotic ED95 through propofolketamine intravenous injection has been reported to contain propofol $0.97 \mathrm{mg} / \mathrm{kg}$ and ketamine $0.33 \mathrm{mg} / \mathrm{kg}$ [21]. Furthermore, ketamine dissociates within 1-2 min after intravenous injection, and the effect is maintained for 10-15 $\min$ [22]. Therefore, it is believed that the addition of a small amount of ketamine to propofol anesthesia through this method deepens anesthesia and is useful in suppressing patient movement.

Propofol may cause vascular pain when intravenously injected, with the frequency reported to be $28-90 \%$ [23] in adults under anesthetic induction and 33-50\% [24] when a small amount of necessary propofol is injected for sedation. In the present study, withdrawal reflex involving the hand or arm, presumed to be caused by vascular pain, was observed in $25.7 \%$ of patients in group P. Although several methods to reduce the frequency and magnitude of vascular pain, such as the addition of lidocaine, have been reported, the addition of ketamine is also an option. It has been reported that the injection of ketamine $0.1-0.15 \mathrm{mg} / \mathrm{kg}$ before intravenous injection of propofol could reduce vascular pain caused by propofol from $84 \%$ to $26 \%$ [7] or from $86.7 \%$ to $46.7 \%$ [8]. In our study, patient movement was observed in $5.8 \%$ of patients in group PK0.2, but none in Group PK0.4, indicating that ketamine contributed to the prevention of vascular pain during intravenous propofol injection.

Some drawbacks of propofol include the relatively higher incidence of dose-dependent hypotension and respiratory depression. Hypotension due to propofol has been reported to be caused by a decrease in systemic vascular resistance and direct myocardial depression [25]. It has also been reported that by simply adding ketamine $0.5 \mathrm{mg} / \mathrm{kg}$, which has a sympathomimetic effect, before the intravenous injection of propofol, hemodynamics during procedures can be maintained at levels comparable with those during control [26]. The cases in this study were different from those in previous studies in that MBP and $\mathrm{HR}$ in group P and groups PK0.2 and PK0.4 tended to decrease over time when compared with those in the control. However, the changes were not significant, and there were no differences among the 3 groups at all time points of measurement. Because MBP in the PK groups did not increase dose-dependently, the intravenous injection with low-dose ketamine $<0.4 \mathrm{mg} / \mathrm{kg}$ may not have affected the circulatory system. Propofol has been reported to cause respiratory depression through the depression of the inspiratory center by decreasing the ratio of tidal volume to inspiratory time [27]. According to clinical research performed in emergency medical care settings, compared with propofol alone, the combination of propofol and ketamine could reduce respiratory depression [28]. In the present study, $\mathrm{SpO}_{2}$ decreased to $<95 \%$ in $27 \%$ of patients in group $\mathrm{P}$ and approximately $16 \%$ in the PK groups; however, there was no statistically significant difference between the two groups, and all incidences of $\mathrm{SpO}_{2}$ reduction were resolved through jaw-lift. Thus, the reduction is believed to be caused by transient airway obstruction due to glossoptosis. In this 
study, clinically problematic circulatory depression and respiratory depression were not observed in group $\mathrm{P}$ and there was no difference when compared with both the PK groups. In other words, the addition of low-dose ketamine $<0.4 \mathrm{mg} / \mathrm{kg}$ in propofol anesthesia was considered to have no effect on the circulatory and respiratory systems.

Complications of deep sedation with propofol-ketamine combination include vomiting and mental abnormalities, including hallucination. Although propofol has demonstrated an anti-nausea effect through dopamine $\mathrm{D}_{2}$ receptor antagonism, it is reported that the frequency of nausea after propofol-ketamine anesthesia increases as the ketamine dose increases [29]. Although vomiting was not noted in group PK0.2 in the present study, it was observed in 1 of 38 patients in group PK0.4; however, it is unclear whether it was caused by ketamine. It has been reported that mental abnormalities due to ketamine intravenous injection are not observed when the dose is $<1 \mathrm{mg} / \mathrm{kg}$ [30]; however, a previous study reported that $10 \%$ of patients experienced hallucinations after sedation with propofol-ketamine $0.1 \mathrm{mg} / \mathrm{kg}$ [31]. In this study, such abnormal behaviors were not observed.

In propofol deep sedation, in contrast to intravenous injection of propofol alone, prior intravenous injection of low-dose ketamine $(0.4 \mathrm{mg} / \mathrm{kg})$ is clinically useful because it neither affects recovery nor causes side effects and can suppress patient movement during procedures as well as vascular pain.

\section{AUTHOR OROHIS}

Akira Hirayama: https://orcid.org/0000-0002-4536-2342

Ken-ichi Fukuda: https://orcid.org/0000-0003-3522-746X

Yoshihiko Koukita: https://orcid.org/0000-0001-9856-0695

Tatsuya Ichinohe: https://orcid.org/0000-0001-5793-3379

CONFLICTS OF INTEREST: There are no conflicts of interest to declare.

\section{REFERENCES}

1. Antila H, Valli J, Valtonen M, Kanto J. Comparison of propofol infusion and isoflurane for maintenance of anesthesia for dentistry in mentally retarded patients. Anesth Prog 1992; 39: 83-6.

2. van der Bijl P, Roelofse JA. Propofol and midazolam for conscious sedation in a mentally retarded patient. Anesth Prog 1992; 39: 36-7.

3. McLeskey $\mathrm{CH}$, Walawander CA, Nahrwold ML, Roizen MF, Stanley TH, Thisted RA, et al. Adverse events in a multicenter phase IV study of propofol: evaluation by anesthesiologists and postanesthesia care unit nurses. Anesth Analg 1993; 77: S3-S9.

4. Short SM, Aun CS. Haemodynamic effects of propofol in children. Anaesthesia 1991; 46: 783-5.

5. Smith I, White PF, Nathanson M, Gouldson R. Propofol: an update on its clinical use. Anesthesiology 1994: 81: 100543.

6. White PF, Way WL, Trevor AJ. Ketamine: its pharmacology and therapeutic uses. Anesthesiology 1982; 56: 11936.

7. Tan $\mathrm{CH}$, Onsiong MK, Kua SW. The effect of ketamine pretreatment on propofol injection pain in 100 women. Anaesthesia 1998; 53: 302-5.

8. Koo SW, Cho SJ, Kim YK, Ham KD, Hwang JH. Small-dose ketamine reduces the pain of propofol injection. Anesth Analg 2006; 103: 1444-7.

9. Roback MG, Wathen JE, Bajaj L, Bothner JP. Adverse events associated with procedural sedation and analgesia in a pediatric emergency department: a comparison of common parenteral drugs. Acad Emerg Med 2005; 12: 508-13.

10. Kramer KJ, Ganzberg S, Prior S, Rashid RG. Comparison of propofol-remifentanil versus propofo-ketamine deep sedation for third molar surgery. Anesth Prog 2012; 59: 107-117.

11. Arora S. Combining ketamine and propofol ("ketofol") for emergency department procedural sedation and analgesia: a review. West J Emerg Med 2008; 9: 20-3. 
12. Jalili M, Bahreini M, Doosti-Irani A, Masoomi R, Arbab M, Mirfazaelian H. Ketamine-propofol combination (ketofol) vs propofol for procedural sedation and analgesia: systematic review and meta-analysis. Am J Emerg Med 2016; 34: 558-69.

13. Alderete JA. The post-anesthesia recovery score revisited. J Clin Anesth 1995; 7: 89-91.

14. Chung F, Chan VW, Ong D. A post-anesthetic discharge scoring system for home readiness after ambulatory surgery. J Clin Anesth 1995; 7: 500-6.

15. Shevchenko Y, Jocson JC, McRae VA, Stayer SA, Schwartz $\mathrm{RE}$, Rehman $\mathrm{M}$, et al. The use of lidocaine for preventing the withdrawal associated with the injection of rocuronium in children and adolescents. Anesth Analg 1999; 88: 746-8.

16. Casagrande AM. Propofol for office oral and maxillofacial anesthesia: the case against low-dose ketamine. J Oral Maxillofac Surg 2006; 64: 693-5.

17. Bennett J, Shafer DM, Efaw D, Goupil M. Incremental bolus versus a continuous infusion of propofol for deep sedation/general anesthesia during dentoalveolar surgery. J Oral Maxillofac Surg 1998; 56: 1049-53.

18. Akin A, Esmaoglu A, Tosun Z, Gulcu N, Aydogan H, Boyaci A. Comparison of propofol with propofol-ketamine combination in pediatric patients undergoing auditory brainstem response testing. Int J Pediatr Otorhinolaryngol 2005; 69: 1541-5.

19. Cillo JE Jr. Analysis of propofol and low-dose ketamine admixtures for adult outpatient dentoalveolar surgery: a prospective, randomized, positive-controlled clinical trial. J Oral Maxillofac Surg 2012; 70: 537-46.

20. Canpolat DG, Yildirim MD, Aksu R, Kutuk N, Alkan A, Cantekin K. Intravenous ketamine, propofol and propofol-ketamine combination used for pediatric dental sedation: A randomized clinical study. Pak J Med Sci 2016; 32: $682-7$

21. Hui TW, Short TG, Hong W, Suen T, Gin T, Plummer J. Additive interactions between propofol and ketamine when used for anesthesia induction in female patients. Anesthesiology 1995; 82: 641-8.

22. Strayer RJ, Nelson LS. Adverse events associated with ketamine for procedural sedation in adults. Am J Emerg Med 2009; 27: 512

23. Tan $\mathrm{CH}$, Onsiong MK. Pain on injection of propofol. Anaesthesia 1998; 53: 468-76.

24. White PF, Negus JB. Sedative infusion during local and regional anesthesia: a comparison of midazolam and propofol. J Clin Anesth 1991; 3: 32-9.

25. Atashkhoyi S, Negargar S, Hatami-Marandi P. Effects of the addition of low-dose ketamine to propofol-fentanyl anaesthesia during diagnostic gynaecological laparoscopy. Eur J Obstet Gynecol Reprod Biol 2013; 170: 247-50.

26. Hug CC Jr, McLeskey CH, Nahrwold ML, Roizen MF, Stanley TH, Thisted RA, et al. Hemodynamic effects of propofol: data from over 25,000 patients. Anesth Analg 1993; 77: S21-S29.

27. Grounds RM, Maxwell DL, Taylor MB, Aber V, Royston D. Acute ventilatory changes during i.v. induction of anaesthesia with thiopentone or propofol in man. Br J Anaesth 1987; 59: 1098-102.

28. Yan JW, Mcleod SL, Iansavitchene A. Ketamine-propofol versus propofol alone for procedural sedation in the emergency department: A systematic review and meta-analysis. Acad Emerg Med 2015; 22: 1003-13.

29. Badrinath S, Avramov MN, Shadrick M, Witt TR, Ivankovich $\mathrm{AD}$. The use of a ketamine-propofol combination during monitored anesthesia care. Anesth Analg 2000; 90: 858-62.

30. Kwok RF, Lim J, Chan MT, Gin T, Chiu WK. Preoperative ketamine improves postoperative analgesia after gynecologic laparoscopic surgery. Anesth Analg 2004; 98: 1044-9.

31. Frizelle HP, Duranteau J, Samii K. A comparison of propofol with a propofol-ketamine combination for sedation during spinal anesthesia. Anesth Analg 1997; 84: 1318-22. 